\title{
Supported Lipid Bilayers of Escherichia coli Extracted Lipids and Their Calcium Dependence
}

\author{
Yasuhiro Kakimoto and Ryugo Tero* \\ Department of Environmental and Life Sciences, Toyohashi University of Technology, Toyohashi, Japan
}

Formation of supported lipid bilayer (SLB) and additional structures of Escherichia coli (E. coli) lipids were investigated with fluorescence microscopy and atomic force microscopy. $\mathrm{Ca}^{2+}$ in the aqueous phase with concentration above $2 \mathrm{mM}$ was necessary for the formation of SLB. Additional lipid structures, string-like structures, the second lipid bilayer, and multilayer stacking appeared on the first layer SLB depending on $\mathrm{Ca}^{2+}$ concentration. The bridging effect of $\mathrm{Ca}^{2+}$ between the negatively charged $E$. coli lipid bilayers and substrate is the dominant factor determining the two-dimensional and three-dimensional morphology of the $E$. coli lipid bilayer membranes.

Keywords: supported lipid bilayer, E. coli lipid, lipid organization, atomic force microscopy, fluorescence microscopy, fluorescence recovery after photobleaching

\section{OPEN ACCESS}

Edited by:

Nam-Joon Cho,

Nanyang Technological University,

Singapore

Reviewed by:

M. Gabriella Santonicola,

Sapienza Università di Roma, Italy

Jun-ichi Hotta

Yamagata University, Japan

*Correspondence:

Ryugo Tero

tero@tut.jp

Specialty section:

This article was submitted to Colloidal Materials and Interfaces,

a section of the journal

Frontiers in Materials

Received: 31 May 2018

Accepted: 31 July 2018

Published: 21 August 2018

Citation:

Kakimoto $Y$ and Tero $R$ (2018)

Supported Lipid Bilayers of

Escherichia coli Extracted Lipids and

Their Calcium Dependence.

Front. Mater. 5:48.

doi: 10.3389/fmats.2018.00048

\section{INTRODUCTION}

Two- and three-dimensional organization of lipid bilayer structures are essential processes in signal and material transportations through cell membranes (Kim, 2006; Rutter, 2006; Rothman, 2014). Artificial lipid membrane is widely used for studying cell membrane property, drug development, and biosensor (Hirano-Iwata et al., 2008). Supported lipid bilayers (SLBs) are a kind of artificial lipid membranes situated at solid-liquid interface (Tamm and McConnell, 1985; Castellana and Cremer, 2006; Tero, 2012; van Weerd et al., 2015). They are used to investigate the fundamental physicochemical properties and molecular distribution of lipid bilayers with atomic force microscopy (AFM) and fluorescence-microscope-based methods (El Kirat et al., 2010; Tero, 2012; Zhong and He, 2012). Morphology and physicochemical properties of lipid domains, and shape transformation of membranes have been studied in multicomponent SLBs (El Kirat et al., 2010; Goertz et al., 2011; Zhong and He, 2012; Kawakami et al., 2017; Sumitomo and Oshima, 2017; Tero et al., 2017; Kakimoto et al., 2018).

As a bacterial model cell system, reconstituted Escherichia coli (E. coli) cell membrane has been studied (Dodd et al., 2008; Merz et al., 2008; Lopes et al., 2010; Unsay et al., 2013; Lind et al., 2015; Phan and Shin, 2015; Hsia et al., 2016; Konarzewska et al., 2017; Márquez and Vélez, 2017). Understanding the bacterial membrane system helps in revealing the mechanism of molecular recognition and material transportation during bacterial infection for medical technology. The E. coli lipid extract contains three main phospholipids, phosphatidylethanolamine (PE), phosphatidylglycerol (PG), and cardiolipin (CA). Neutral PE is most abundant in the E. coli cell membranes, and anionic PG and CA make the membrane net negatively charged (Shokri and Larsson, 2004; Romantsov et al., 2007; Gidden et al., 2009; Sohlenkamp and Geiger, 2015; Lin and Weibel, 2016). In addition, CA exists in the high curvature region of membrane and plays a key role in antimicrobial peptide interaction (Khalifat et al., 2008; Lewis and McElhaney, 2009; Mileykovskaya and Dowhan, 2009; Schlame and Ren, 2009; Lopes et al., 2010; Unsay et al., 2013; Phan and Shin, 2015). 
There are several previous studies on the formation of SLBs containing E. coli lipids such as polar lipid extract (PLE) or total lipid extract (TLE) (Dodd et al., 2008; Merz et al., 2008; Lopes et al., 2010; Unsay et al., 2013; Lind et al., 2015; Hsia et al., 2016; Konarzewska et al., 2017; Márquez and Vélez, 2017). Solid substrates, which are generally used for SLB formation, e.g., glass, oxidized layer on a $\mathrm{Si}$ wafer, and mica, are negatively charged. Because of the electrostatic repulsion between negatively charged $E$. coli lipids and the substrates, divalent cation such as $\mathrm{Ca}^{2+}$ is necessary to form SLB (Merz et al., 2008; Lind et al., 2015; Márquez and Vélez, 2017). Previous QCM and fluorescence microscope studies showed that $\sim 2 \mathrm{mM} \mathrm{Ca}^{2+}$ is sufficient for the formation of E. coli lipid SLB (Merz et al., 2008; Lind et al., 2015; Márquez and Vélez, 2017). Divalent cations bridge negatively charged substances by effectively shielding electrostatic interaction (Rajendran et al., 2011; Ido et al., 2013), and also positively affect the SLB formation from lipid vesicles (Hansma and Laney, 1996; Rivetti et al., 1996; Reviakine and Brisson, 2000; Pastré et al., 2003; Seantier and Kasemo, 2009). $\mathrm{Ca}^{2+}$ also induces microstructure of lipid bilayers containing negatively charged lipids. For example, phase separation and membrane fusion of lipid bilayers containing phosphatidylserine is caused by $\mathrm{Ca}^{2+}$ (Silvius and Gagne, 1984a,b). In this study, we investigated microscopic two-dimensional and three-dimensional organization of lipid membranes comprising of PLE and their dependence on $\mathrm{Ca}^{2+}$ concentration $\left(\left[\mathrm{Ca}^{2+}\right]\right)$ with fluorescence microscopy and AFM.

\section{MATERIALS AND METHODS}

PLE [PE: PG: CA = 67: 23.2: 9.8 (wt/wt)] and lissamine rhodamine B-dipalmitoylphosphatidylethanolamine (Rb-DPPE, Ex/Em: 560/583 nm) were purchased from Avanti Polar Lipids, Inc., (Alabaster, AL, USA), and used without purification. The lipid ratio among $\mathrm{PE}, \mathrm{PG}$ and $\mathrm{CA}$ corresponds to that in $E$. coli (Merz et al., 2008; Lopes et al., 2010; Lind et al., 2015). Chloroform solutions of PLE and Rb-DPPE were mixed in a glass vial. The solution was dried with a nitrogen gas stream followed by overnight evacuation. A buffer solution $(120 \mathrm{mM} \mathrm{KCl}$ and $10 \mathrm{mM}$ HEPES/KOH: $\mathrm{pH}$ 7.2) was added to the vacuumdried lipid mixture film. A lipid vesicle suspension was then prepared by vortex at $45^{\circ} \mathrm{C}$, freeze-thawing through five cycles, and extruding through 800 and $100 \mathrm{~nm}$ polycarbonate filters. SLB was prepared by the vesicle fusion method on a thermally oxidized $\mathrm{SiO}_{2} / \mathrm{Si}$ substrate precleaned by boiling in piranha solution (3:1 v/v mixture of conc. $\mathrm{H}_{2} \mathrm{SO}_{4}$ and $30 \% \mathrm{H}_{2} \mathrm{O}_{2}$ aqueous solution). Caution: Piranha solution violently reacts with organic materials, and extreme care must be taken at all times during handling.

We mixed the extruded vesicle suspension and a $\mathrm{Ca}^{2+}$. containing buffer solution $\left(10 \mathrm{mM} \mathrm{CaCl}_{2}, 120 \mathrm{mM} \mathrm{KCl}, 10 \mathrm{mM}\right.$ HEPES/KOH: $\mathrm{pH} 7.2$ ), and incubated the $\mathrm{SiO}_{2} / \mathrm{Si}$ substrate under $\left[\mathrm{Ca}^{2+}\right]=0-8 \mathrm{mM}$, at $45^{\circ} \mathrm{C}$ for $90 \mathrm{~min}$. After the incubation, the excess vesicles in the liquid phase were washed out by serial exchanges of the vesicle suspension with buffer solution.
An epi-fluorescence microscope (epi-FM) (BX51WI, Olympus, Tokyo, Japan) was used for wide-field fluorescence and qualitative fluorescence recovery after photobleaching (FRAP) observations. AFM observation was performed using the PicoPlus 5500 (Keysight Technologies, Inc., Santa Rosa, CA, USA, formerly Molecular Imaging, Corp.) in the acoustic AC (tapping) mode in the buffer solution. A cantilever with a spring constant of $0.09 \mathrm{~N} / \mathrm{m}$ (resonant frequency: $110 \mathrm{kHz}$ BL-AC40TS-C2, Olympus) was used. Topography, phase-shift image, and amplitude image were obtained simultaneously.

\section{RESULTS AND DISCUSSION}

Figure 1 shows fluorescence images of the $\mathrm{SiO}_{2} / \mathrm{Si}$ substrates after incubated in the PLE-vesicle suspensions with $0,2.0,2.5,3.0$, and $5.0 \mathrm{mM} \mathrm{Ca}^{2+}$. With $\left[\mathrm{Ca}^{2+}\right]=0 \mathrm{mM}$ (Figure 1A), almost no fluorescence intensity was obtained except for a few bright spots, which were adsorbed vesicles. When the substrate was incubated in the PLE-suspension with $\left[\mathrm{Ca}^{2+}\right]=2 \mathrm{mM}$, a circular region with a uniform fluorescence intensity existed (Figure 1B). The fluorescence intensity shows that single layer of SLB was formed in this region (Tero et al., 2017; Kakimoto et al., 2018). The surrounding gray region contained bright dots that had similar fluorescence intensity to the circular SLB region (Figure 1B, inset). They are assigned to small SLB patches. Coverage of the larger SLB region and the surrounding SLB did not change at longer incubation time.

The surface morphology became heterogeneous with $\left[\mathrm{Ca}^{2+}\right]$ $=2.5 \mathrm{mM}$ : a circular SLB and smaller SLB patches similar to Figure 1B existed (Figure 1C), and additional brighter objects were also observed in the SLB region with a uniform fluorescence intensity (Figure 1D). The latter region covered almost the whole substrate surface with $\left[\mathrm{Ca}^{2+}\right]=3.0 \mathrm{mM}$ (Figure 1E). There were two types of bright objects on SLB (Figure 1E, inset). One was string-like structures (indicated by a white arrow in Figure 1E). The other was brighter regions (indicated by a black arrow in Figure 1E) that had two times higher intensity than the surrounding, and had a plateau-like intensity profile. We assigned them to the second lipid bilayer stacking on the first SLB, based on the fluorescence intensity (Nabika et al., 2006; Tero et al., 2008). These structures disappeared with $\left[\mathrm{Ca}^{2+}\right]=$ $5.0 \mathrm{mM}$, and much brighter objects were observed in a uniform fluorescence intensity (Figure 1F). They had at least four times higher fluorescence intensity than the surrounding that had similar intensity with the SLB region in Figure 1E. Similar fluorescence images to Figure $\mathbf{1 F}$ were obtained with higher $\left[\mathrm{Ca}^{2+}\right]$ up to $8 \mathrm{mM}$ (data not shown).

Figure 2 shows the FRAP process of PLE-SLBs with $\left[\mathrm{Ca}^{2+}\right]$ $=2.0,3.0$, and $5.0 \mathrm{mM}$. FRAP is a fluorescence-microscopebased technique to measure lateral molecular diffusion in a lipid bilayer (Axelrod et al., 1976; Soumpasis, 1983). Fluorescent probes at a part of a sample are bleached with strong excitation light, and then the fluorescence intensity recovers if the probes diffuse. We investigated the fluidity and continuity of the SLB and the brighter objects observed in the fluorescence images in Figure 1. The fluorescence intensity of the small SLB patches 

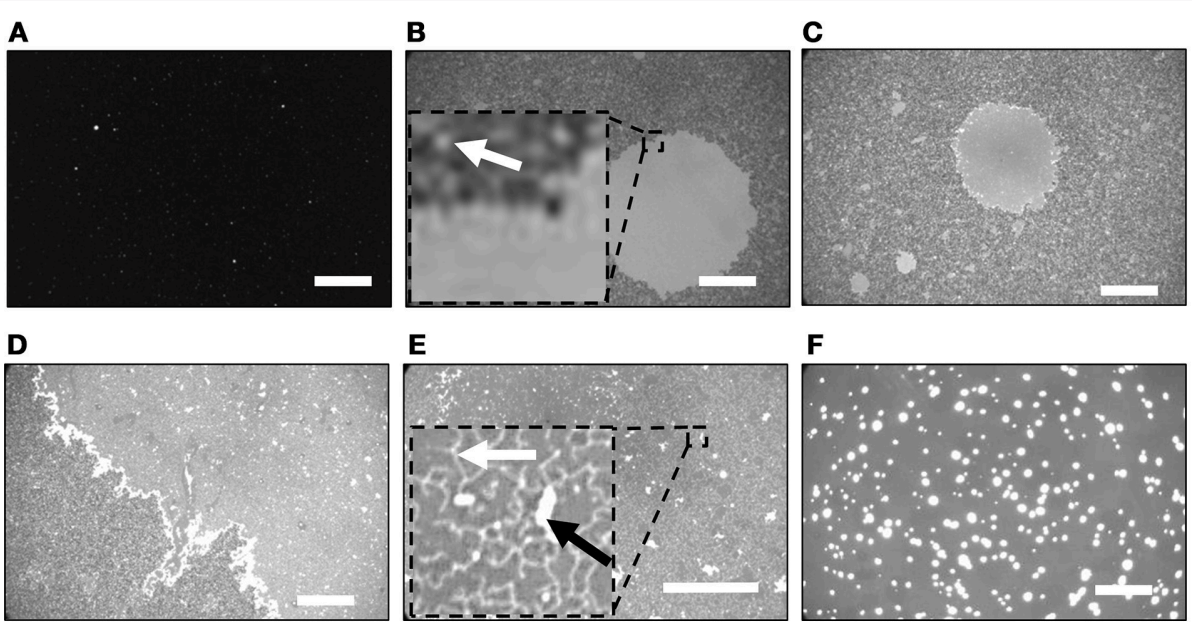

FIGURE 1 | Fluorescence images of $\mathrm{SiO}_{2} / \mathrm{Si}$ substrates after incubated in the PLE-vesicle suspensions with [Ca $\left.{ }^{2+}\right]=(\mathbf{A}) 0$, (B) 2.0 , (C,D) 2.5, (E) 3.0, and (F) $5.0 \mathrm{mM}$. (B,E) Insert: magnified image of the dotted square region. Representative SLB patch is indicated with a white arrow in (B). The string-like structure and the region two times brighter than the surrounding are indicated with a white arrow and a black arrow in (E), respectively. Scale bars are $50 \mu \mathrm{m}$.

A

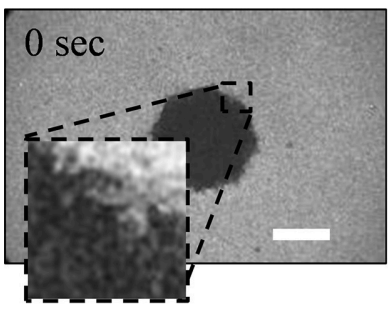

B

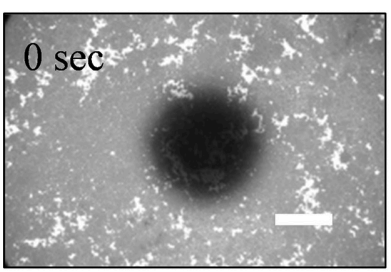

C

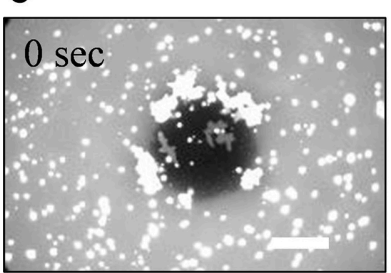

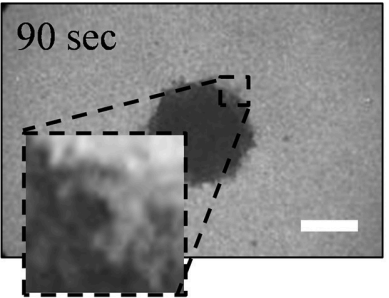
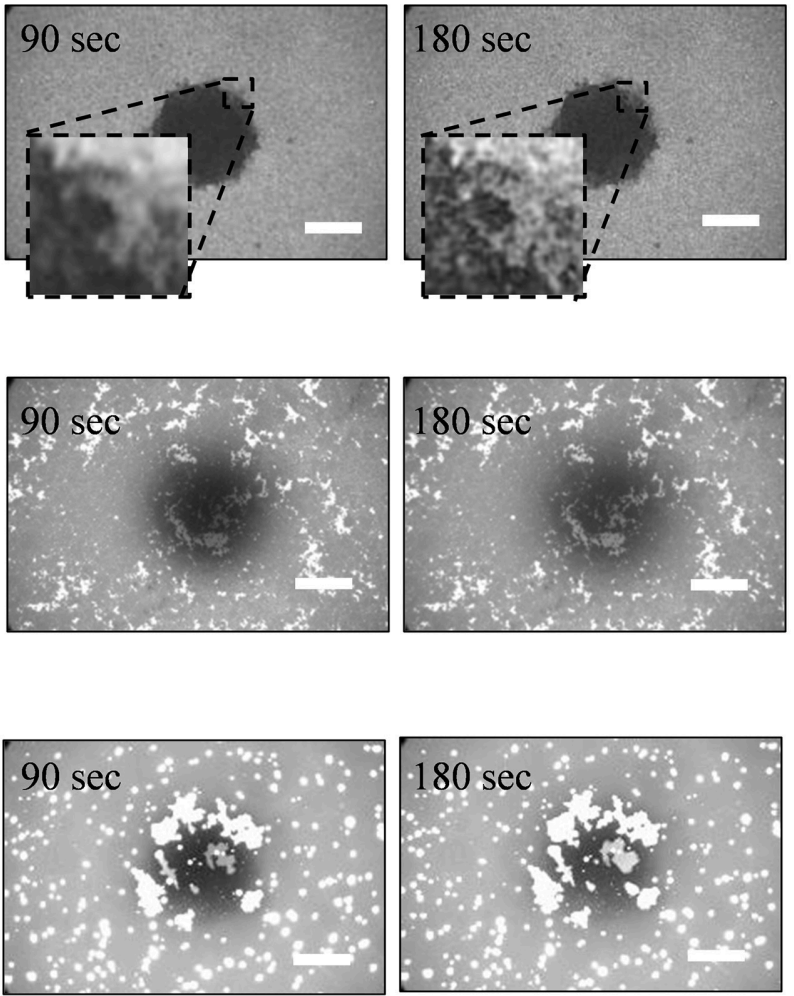

FIGURE 2 | Fluorescence recovery after photobleaching (FRAP) processes of PLE-SLBs with $\left[\mathrm{Ca}^{2+}\right]=(\mathbf{A}) 2.0 \mathrm{mM}$, (B) $3.0 \mathrm{mM}$, and (C) $5.0 \mathrm{mM}$. Scale bars are $50 \mu \mathrm{m}$.

with $\left[\mathrm{Ca}^{2+}\right]=2.0 \mathrm{mM}$ (the gray region in Figure 1B) partially recovered at the peripheral of the bleached region (Figure 2A), but did not recovered in the majority of the bleached region. The result indicates that the SLB patches did not link each other.
In the region with uniform fluorescence intensity (the circular bright region in Figure 1B), fluorescence intensity completely recovered. The fluorescence intensity recovered over time in PLE-SLB with $\left[\mathrm{Ca}^{2+}\right]=3.0$ (Figure $2 \mathrm{~B}$ ). These results show that 
fluid and continuous SLB was formed in the region with uniform intensity. The fluorescence of the brighter objects, the stringlike structure and the second layer of the bilayer membrane (Figure 1E), also recovered completely (Figure 2B). It indicates that these objects are linked with the SLB under them, and lipid molecules diffuse between them. In the PLE-SLB with $\left[\mathrm{Ca}^{2+}\right]$ $=5.0 \mathrm{mM}$, FRAP proceeded both in SLB and the bright objects (Figure 2C).

Figure 3 shows AFM topographies and cross-section profiles obtained at various positions of PLE-SLB with $\left[\mathrm{Ca}^{2+}\right]=2.5 \mathrm{mM}$. As shown in Figures 1 B,C, the sample with $\left[\mathrm{Ca}^{2+}\right]=2.5 \mathrm{mM}$ contained all kinds of structures, the SLB patches, uniform SLB, the string-like structure and the second layer on SLB, which were observed in the fluorescence images of $2 \mathrm{mM}$ and $3 \mathrm{mM} \mathrm{Ca}^{2+}$. Three types of structures were obtained with AFM observation: plateaus $4-5 \mathrm{~nm}$ in height and $\sim 10-1,000 \mathrm{~nm}$ in width (Figure 3A); flat and uniform region (Figure 3B); network-like protrusions $2-3 \mathrm{~nm}$ in height (Figure 3C). The network-like protrusions were fragile, and disappeared after the same area was scanned repeatedly.

The height of the plateaus in Figure $\mathbf{3 A}$ corresponds to the thickness of a single lipid bilayer membrane in AFM topographies (Tero, 2012). Therefore we attribute the plateaus to the SLB patches observed in Figures 1B-D, 2A. The SLB patches of the order of $1 \mu \mathrm{m}$ in width were recognized in the fluorescence images (Figure 1). FRAP proceeded partially (Figure 2A), as some of these patches linked each other (Figure 3A). The AFM topography in Figure 3A shows that small SLB patches 10$100 \mathrm{~nm}$ in width existed, although they were not recognized in the optical images (Figure 1).

The flat region in Figure $3 \mathbf{B}$ corresponds to a continuous SLB in Figures 2B,C. The AFM topography shows that the SLB was defect-free on the order of micrometer in wide, and surface roughness was $\sim 1 \mathrm{~nm}$. We attribute the network-like protrusions in Figure 3C to the string-like structure in the fluorescence image in Figure 1C. We hypothesize that they are tubular bilayers or wrinkles in a SLB, but could not achieve detailed observation because they were easily decomposed by AFM scanning. In the AFM topographies, we did not find objects corresponding to the double bilayer region, which was two times brighter than the surrounding SLB in the fluorescence image (Figure 1E). It is because that the area fraction of the second bilayer is small $(2.5 \%$ in Figure 1E). The AFM scanning area $(2-3 \mu \mathrm{m})$ was smaller than the width of the second bilayer $(\sim 10 \mu \mathrm{m})$. Single or double bilayer is not recognized with AFM if they are similarly flat, unless the edge of the second bilayer is captured in the AFM scanning area.

Formation and morphology of the PLE-SLB significantly depended on $\left[\mathrm{Ca}^{2+}\right]$. PLE-bilayer is negatively charged at neutral $\mathrm{pH}$ because of PG and CA. In this study, PLE vesicles transformed to SLB and other structures on the SLB. SLB formation from vesicles proceeded through the processes of vesicle adsorption, fusion, rupture and spreading. With $\left[\mathrm{Ca}^{2+}\right]=0 \mathrm{mM}$, few lipid components existed on the $\mathrm{SiO}_{2} / \mathrm{Si}$ substrate (Figure 1A), which is negatively charged because of the dissociation of surface silanol group (Si-OH) (Ahmed, 1966; Tero, 2012). Electrostatic repulsion between the PLE vesicle and the substrate suppressed the vesicle adsorption process.

Divalent cations shield the electrostatic interaction more effectively than monovalent cations, and also bridge electronegative substances, e.g., DNA and a mica substrate (Rajendran et al., 2011; Ido et al., 2013). Addition of $\mathrm{Ca}^{2+}$ promoted the vesicle adsorption and SLB formation on the $\mathrm{SiO}_{2} / \mathrm{Si}$ substrate (Figure 1B). The result is consistent with

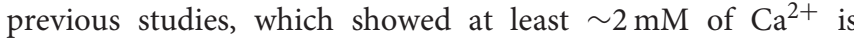
necessary for the formation of PLE-SLB on $\mathrm{SiO}_{2} / \mathrm{Si}$, mica, $\mathrm{TiO}_{2}$, indium tin oxide and gold (Dodd et al., 2008; Merz et al., 2008; Lopes et al., 2010; Unsay et al., 2013; Lind et al., 2015; Hsia et al., 2016; Konarzewska et al., 2017; Márquez and Vélez, 2017). In the previous studies of the bacterial mimic lipid bilayer, however, averaged response from the sample was mainly obtained using QCM and fluorescence microscopy (Dodd et al., 2008; Merz et al., 2008; Lopes et al., 2010; Unsay et al., 2013; Lind et al., 2015; Phan and Shin, 2015; Hsia et al., 2016; Konarzewska et al., 2017; Márquez and Vélez, 2017). The results in this study showed the heterogeneity of SLB especially at the threshold $\left[\mathrm{Ca}^{2+}\right]$ around $2.5 \mathrm{mM}$. Density of adsorbed $\mathrm{Ca}^{2+}$ on substrates depends on $\left[\mathrm{Ca}^{2+}\right]$ in the bulk solution. Fluorescence images in Figure 1 shows that $\mathrm{Ca}^{2+}$ of $2-2.5 \mathrm{mM}$ induced formation of the negatively charged PLE-SLB, but was not enough for the formation of full-coverage SLB. Under the bulk concentration of $\left[\mathrm{Ca}^{2+}\right]=$ $3 \mathrm{mM}$, sufficient amount of $\mathrm{Ca}^{2+}$ existed between the PLE-SLB and the substrate for bridging them in the whole substrate surface.

Generally only a single layer of lipid bilayer membrane is formed in the SLB formation from small unilamellar vesicles (Tero, 2012), unless a specific attraction is introduced between the first and second layer (Murray et al., 2009; Han et al., 2010). In this study, inter-lipid-bilayer bridging was caused by $\mathrm{Ca}^{2+}$ more than $2 \mathrm{mM}$, as well as the substrate-lipidbilayer bridging, and thus additional PLE-derived structures appeared on the first layer PLE-SLB. More PLE existed with higher $\left[\mathrm{Ca}^{2+}\right]$ (Figures 1D-F), and their structures depended on $\left[\mathrm{Ca}^{2+}\right]$. At $\left[\mathrm{Ca}^{2+}\right]=3 \mathrm{mM}$, the string-like structure and the second bilayer patch bound to the first layer PLE-SLB, and they were isolated from each other. At $\left[\mathrm{Ca}^{2+}\right]=5-$ $8 \mathrm{mM}$, on the other hand, attraction between the additional lipid membranes became dominant, and multi-layer stacking or segregation of PLE bilayers occurred. They kept the lipid bilayer structure, and also physically connected to the first layer PLE-SLB, because fluorescence intensity recovered in the FRAP experiment (Figure 2C).

Figure 4 shows time course of fluorescence images of PLESLBs with $\left[\mathrm{Ca}^{2+}\right]=3 \mathrm{mM}$, observed just after the PLE-SLBs were prepared. The amount of the string-like structure on the uniform lipid bilayer decreased with time (Figure 4A). The area of the second bilayer also decreased with time, leaving the string-like structures (Figure 4B). These images provide information about the formation process of these additional structures on the first layer PLE-SLB. The second layer remained on the first layer because of the $\mathrm{Ca}^{2+}$. bridging effect, at the process of the spreading during the 

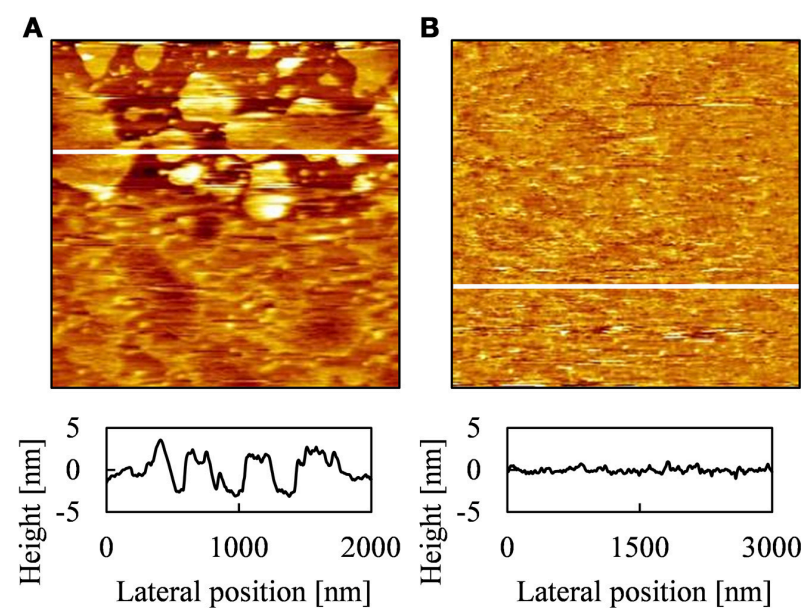
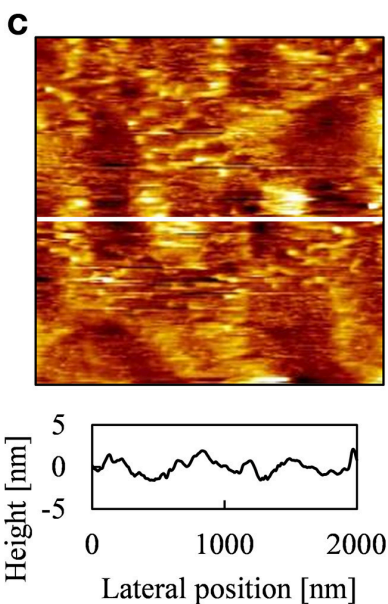

FIGURE 3 | AFM topographies and cross-section profiles of PLE-SLB with $\left[\mathrm{Ca}^{2+}\right]=2.5 \mathrm{mM}$ obtained at different positions, $[(\mathbf{A}) 2.0 \mu \mathrm{m} \times 2.0 \mu \mathrm{m},(\mathbf{B}) 3.0 \mu \mathrm{m} \times$ $3.0 \mu \mathrm{m}$, (C) $2.0 \mu \mathrm{m} \times 2.0 \mu \mathrm{m}]$ and the cross-section profile at the white line in each AFM topography.
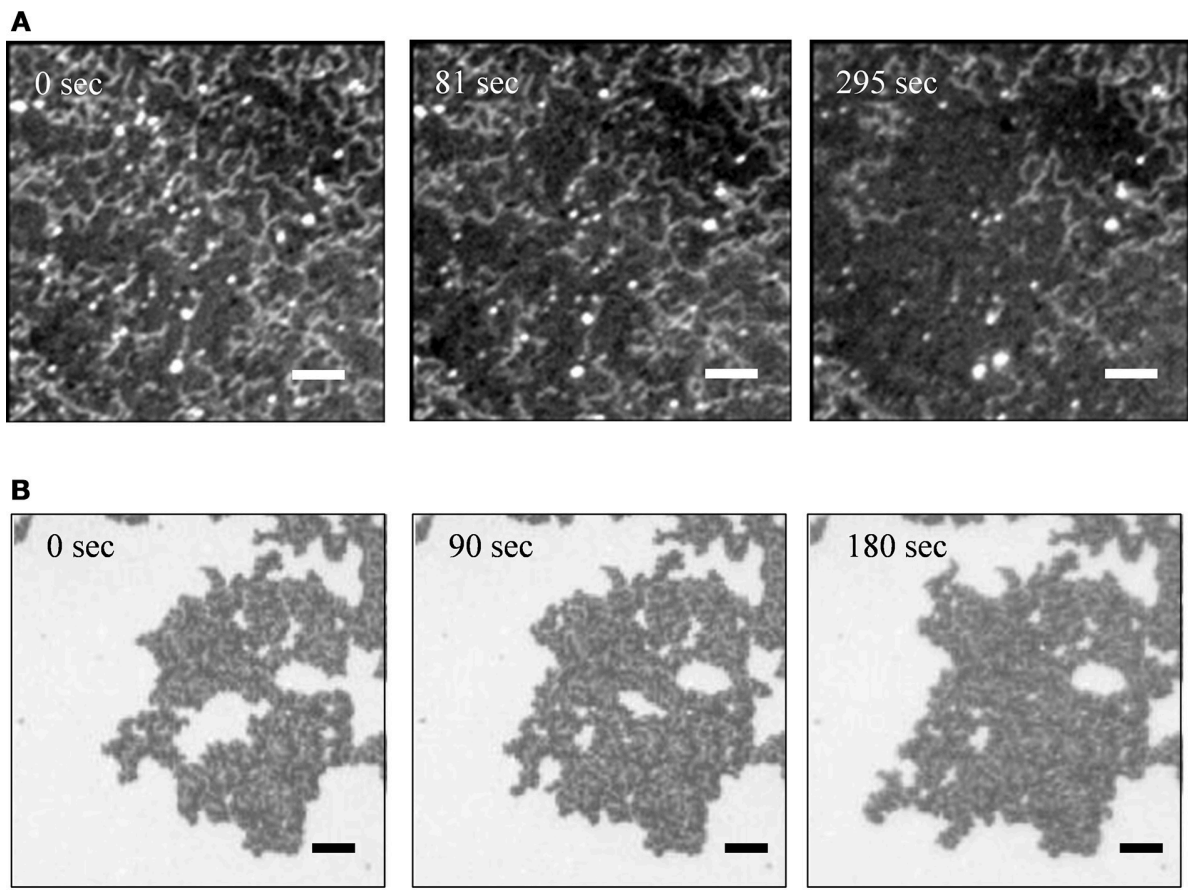

FIGURE 4 | Sequential fluorescence images of PLE-SLBs with $\left[\mathrm{Ca}^{2+}\right]=3.0 \mathrm{mM}$ focusing to $(\mathbf{A})$ the string-like structure and (B) the second bilayer two times brighter than the surrounding. The images of $(\mathbf{A}, \mathbf{B})$ were obtained from two samples independently. Scale bars are $10 \mu \mathrm{m}$.

transformation from vesicles to a planar membrane. Some of the second layers desorbed remaining the string-like structure, which further converted to a uniform SLB. These structural conversions stopped when their adsorption amounts reached at the equilibrium of $\mathrm{Ca}^{2+}$-bridging effect depending on $\left[\mathrm{Ca}^{2+}\right]$. Therefore the brighter objects existed stably in Figures 2B,C.

Intracellular $\left[\mathrm{Ca}^{2+}\right]$ in $E$. coli is approximately $0.1 \mu \mathrm{M}$ (Gangola and Rosen, 1987). E. coli exists, however, in intestine of warm blood animal. Its extracellular fluid is kept at $\left[\mathrm{Ca}^{2+}\right]$ in the order of $\mathrm{mM}$ (Berridge et al., 2000, 2003). Additionally, cell membrane surfaces are negatively charged. From the point of view of biotechnology, generally transformation of $E$. coli with plasmid DNA is conducted in a solution of $\left[\mathrm{Ca}^{2+}\right] \geq 10 \mathrm{mM}$ (Mandel and Higa, 1970; Hanahan, 1983). $\mathrm{Ca}^{2+}$ facilitates insertion of plasmid DNA by suppressing electrostatic repulsion between membrane and DNA, and then bringing membrane pore formation. Figure 1F showed tendency that a PLE bilayers 
to take multilamellar stacking and aggregate states, rather than a planar single bilayer membrane, at $\left[\mathrm{Ca}^{2+}\right] \geq 5 \mathrm{mM}$. The results in this study revealed that the $\mathrm{Ca}^{2+}$ induced the adsorption of PLE bilayer on a negatively charged surface, and also caused structural conversions of the PLE bilayer depending on $\left[\mathrm{Ca}^{2+}\right]$. They will provide information for understanding fundamental processes of infection and transfection of $E$. coli.

\section{CONCLUSION}

In conclusion, we investigated the morphology and physical properties of PLE-SLBs in various $\left[\mathrm{Ca}^{2+}\right]$ with fluorescence microscopy and AFM. $\mathrm{Ca}^{2+}$ facilitated vesicle adsorption and subsequent SLB formation on a negatively charged $\mathrm{SiO}_{2} / \mathrm{Si}$ substrate. Morphologies of the first layer SLB and additional structures on it were strongly affected by $\left[\mathrm{Ca}^{2+}\right]$. Electrostatic bridging effect of $\mathrm{Ca}^{2+}$ is the dominant factor of these phenomena. Understanding two-dimensional and threedimensional inter-membrane structures is valuable to construct model bacterial membranes using SLB systems, and to reveal

\section{REFERENCES}

Ahmed, S. M. (1966). Studies of the dissociation of oxide surfaces at the liquid-solid interface. Can. J. Chem. 44, 1663-1670. doi: 10.1139/v66-251

Axelrod, D., Koppel, D. E., Schlessinger, J., Elson, E., and Webb, W. W. (1976). Mobility measurement by analysis of fluorescence photobleaching recovery kinetics. Biophys. J. 16, 1055-1069. doi: 10.1016/S0006-3495(76)85755-4

Berridge, M. J., Bootman, M. D., and Roderick, H. L. (2003). Calcium signalling: dynamics, homeostasis and remodelling. Nat. Rev. Mol. Cell Biol. 4, 517-529. doi: $10.1038 / \mathrm{nrm} 1155$

Berridge, M. J., Lipp, P., and Bootman, M. D. (2000). The versatility and universality of calcium signalling. Nat. Rev. Mol. Cell Biol. 1, 11-21. doi: $10.1038 / 35036035$

Castellana, E. T., and Cremer, P. S. (2006). Solid supported lipid bilayers: from biophysical studies to sensor design. Surf. Sci. Rep. 61, 429-444. doi: 10.1016/j.surfrep.2006.06.001

Dodd, C. E., Johnson, B. R. G., Jeuken, L. J. C., Bugg, T. D. H., Bushby, R. J., and Evans, S. D. (2008). Native E. coli inner membrane incorporation in solid-supported lipid bilayer membranes. Biointerphases 3, FA59-FA67. doi: $10.1116 / 1.2896113$

El Kirat, K., Morandat, S., and Dufrêne, Y. F. (2010). Nanoscale analysis of supported lipid bilayers using atomic force microscopy. Biochim. Biophys. Acta Biomembr. 1798, 750-765. doi: 10.1016/j.bbamem.2009.07.026

Gangola, P., and Rosen, B. P. (1987). Maintenance of intracellular calcium in Escherichia coli. J. Biol. Chem. 262, 12570-12574.

Gidden, J., Denson, J., Liyanage, R., Ivey, D. M., and Lay, J. O. (2009). Lipid compositions in Escherichia coli and Bacillus subtilis during growth as determined by MALDI-TOF and TOF/TOF mass spectrometry. Int. J. Mass Spectrom. 283, 178-184. doi: 10.1016/j.ijms.2009.03.005

Goertz, M. P., Goyal, N., Montano, G. A., and Bunker, B. C. (2011). Lipid bilayer reorganization under extreme $\mathrm{pH}$ conditions. Langmuir 27, 5481-5491. doi: $10.1021 / \mathrm{la} 2001305$

Han, X., Achalkumar, A. S., Cheetham, M. R., Connell, S. D. A., Johnson, B. R. G., Bushby, R. J., et al. (2010). A self-assembly route for double bilayer lipid membrane formation. Chemphyschem 11, 569-574. doi: $10.1002 /$ cphc. 200900798

Hanahan, D. (1983). Studies on transformation of Escherichia coli with plasmids. J. Mol. Biol. 166, 557-580. doi: 10.1016/S0022-2836(83)80284-8 fundamental processes of bacterial membrane reactions in the field of biotechnology and medicine.

\section{AUTHOR CONTRIBUTIONS}

YK carried out the experiments, and analyzed the data. YK and RT designed the experiment and wrote the paper.

\section{FUNDING}

This work was supported by JSPS KAKENHI Grant Numbers JP15H03768 and JP15H00893, JST-CREST Grant Number JPMJCR14F3, and JST-A-STEP.

\section{ACKNOWLEDGMENTS}

Electronics-Inspired Interdisciplinary Research Institute (EIIRIS) Project, Toyohashi University of Technology, and Nation-wide Cooperative Research Projects, Research Institute of Electrical Communication, Tohoku University are acknowledged.

Hansma, H. G., and Laney, D. E. (1996). DNA binding to mica correlates with cationic radius: assay by atomic force microscopy. Biophys. J. 70, 1933-1939. doi: 10.1016/S0006-3495(96)79757-6

Hirano-Iwata, A., Niwano, M., and Sugawara, M. (2008). The design of molecular sensing interfaces with lipid-bilayer assemblies. TrAC Trends Anal. Chem. 27, 512-520. doi: 10.1016/j.trac.2008.04.006

Hsia, C. Y., Chen, L., Singh, R. R., DeLisa, M. P., and Daniel, S. (2016). A molecularly complete planar bacterial outer membrane platform. Sci. Rep. 6:32715. doi: $10.1038 /$ srep32715

Ido, S., Kimura, K., Oyabu, N., Kobayashi, K., Tsukada, M., Matsushige, K., et al. (2013). Beyond the helix pitch: direct visualization of native DNA in aqueous solution. ACS Nano 7, 1817-1822. doi: 10.1021/nn400071n

Kakimoto, Y., Tachihara, Y., Okamoto, Y., Miyazawa, K., Fukuma, T., and Tero, R. (2018). Morphology and physical properties of hydrophilic-polymermodified lipids in supported lipid bilayers. Langmuir 34, 7201-7209. doi: 10.1021/acs.langmuir. 8 b00870

Kawakami, L. M., Yoon, B. K., Jackman, J. A., Knoll, W., Weiss, P. S., and Cho, N. J. (2017). Understanding how sterols regulate membrane remodeling in supported lipid bilayers. Langmuir 33, 14756-14765. doi: 10.1021/acs.langmuir.7b03236

Khalifat, N., Puff, N., Bonneau, S., Fournier, J. B., and Angelova, M. I. (2008) Membrane deformation under local $\mathrm{pH}$ gradient: mimicking mitochondrial cristae dynamics. Biophys. J. 95, 4924-4933. doi: 10.1529/biophysj.108.136077

Kim, T. (2006). Dense-core secretory granule biogenesis. Physiology 21, 124-133. doi: 10.1152/physiol.00043.2005

Konarzewska, D., Juhaniewicz, J., Güzeloglu, A., and Sek, S. (2017). Characterization of planar biomimetic lipid films composed of phosphatidylethanolamines and phosphatidylglycerols from Escherichia coli. Biochim. Biophys. Acta Biomembr. 1859, 475-483. doi: 10.1016/j.bbamem.2017.01.010

Lewis, R. N. A. H., and McElhaney, R. N. (2009). The physicochemical properties of cardiolipin bilayers and cardiolipin-containing lipid membranes. Biochim. Biophys. Acta Biomembr. 1788, 2069-2079. doi: 10.1016/j.bbamem.2009.03.014

Lin, T. Y., and Weibel, D. B. (2016). Organization and function of anionic phospholipids in bacteria. Appl. Microbiol. Biotechnol. 100, 4255-4267. doi: 10.1007/s00253-016-7468-x

Lind, T. K., Wacklin, H., Schiller, J., Moulin, M., Haertlein, M., Pomorski, T. G., et al. (2015). Formation and characterization of supported lipid bilayers 
composed of hydrogenated and deuterated Escherichia coli lipids. PLoS ONE 10:e0144671. doi: 10.1371/journal.pone.0144671

Lopes, S., Neves, C. S., Eaton, P., and Gameiro, P. (2010). Cardiolipin, a key component to mimic the $E$. coli bacterial membrane in model systems revealed by dynamic light scattering and steady-state fluorescence anisotropy. Anal. Bioanal. Chem. 398, 1357-1366. doi: 10.1007/s00216-010-4028-6

Mandel, M., and Higa, A. (1970). Calcium-dependent bacteriophage DNA infection. J. Mol. Biol. 53, 159-162. doi: 10.1016/0022-2836(70)90051-3

Márquez, I. F., and Vélez, M. (2017). Formation of supported lipid bilayers of charged E. coli lipids on modified gold by vesicle fusion. MethodsX 4, 461-468. doi: 10.1016/j.mex.2017.11.002

Merz, C., Knoll, W., Textor, M., and Reimhult, E. (2008). Formation of supported bacterial lipid membrane mimics. Biointerphases 3, FA41-FA50. doi: $10.1116 / 1.2896119$

Mileykovskaya, E., and Dowhan, W. (2009). Cardiolipin membrane domains in prokaryotes and eukaryotes. Biochim. Biophys. Acta Biomembr. 1788, 2084-2091. doi: 10.1016/j.bbamem.2009.04.003

Murray, D. H., Tamm, L. K., and Kiessling, V. (2009). Supported double membranes. J. Struct. Biol. 168, 183-189. doi: 10.1016/j.jsb.2009.02.008

Nabika, H., Fukasawa, A., and Murakoshi, K. (2006). Control of the structure of self-spreading lipid membrane by changing electrolyte concentration. Langmuir 22, 10927-10931. doi: 10.1021/la062459y

Pastré, D., Piétrement, O., Fusil, S., Landousy, F., Jeusset, J., David, M. O., et al. (2003). Adsorption of DNA to mica mediated by divalent counterions: a theoretical and experimental study. Biophys. J. 85, 2507-2518. doi: 10.1016/S0006-3495(03)74673-6

Phan, M. D., and Shin, K. (2015). Effects of cardiolipin on membrane morphology: a langmuir monolayer study. Biophys. J. 108, 1977-1986. doi: 10.1016/j.bpj.2015.03.026

Rajendran, A., Endo, M., Katsuda, Y., Hidaka, K., and Sugiyama, H. (2011). Programmed two-dimensional self-assembly of multiple DNA origami jigsaw pieces. ACS Nano 5, 665-671. doi: 10.1021/nn1031627

Reviakine, I., and Brisson, A. (2000). Formation of supported phospholipid bilayers from unilamellar vesicles investigated by atomic force microscopy. Langmuir 16, 1806-1815. doi: 10.1021/la9903043

Rivetti, C., Guthold, M., Bustamante, C., and Medical, H. H. (1996). Scanning force microscopy of DNA deposited onto mica: equilibration versus kinetic trapping studied by statistical polymer chain analysis. J. Mol. Biol. 264, 919-932. doi: 10.1006/jmbi.1996.0687

Romantsov, T., Helbig, S., Culham, D. E., Gill, C., Stalker, L., and Wood, J. M. (2007). Cardiolipin promotes polar localization of osmosensory transporter ProP in Escherichia coli. 64, 1455-1465. doi: 10.1111/j.1365-2958.2007.05727.x

Rothman, J. E. (2014). The principle of membrane fusion in the cell (Nobel lecture). Angew. Chem. Int. Ed. 53, 12676-12694. doi: 10.1002/anie.201402380

Rutter, G. A. (2006). Insulin vesicle release: walk, kiss, pause... then run. Physiology 21, 189-196. doi: 10.1152/physiol.00002.2006

Schlame, M., and Ren, M. (2009). The role of cardiolipin in the structural organization of mitochondrial membranes. Biochim. Biophys. Acta Biomembr. 1788, 2080-2083. doi: 10.1016/j.bbamem.2009.04.019

Seantier, B., and Kasemo, B. (2009). Influence of mono- and divalent ions on the formation of supported phospholipid bilayers via vesicle adsorption. Langmuir 25, 5767-5772. doi: 10.1021/la804172f
Shokri, A., and Larsson, G. (2004). Characterisation of the Escherichia coli membrane structure and function during fedbatch cultivation. Microb. Cell Fact. 3, 1-12. doi: 10.1186/1475-2859-3-9

Silvius, J. R., and Gagne, J. (1984a). Calcium-induced fusion and lateral phase separations in phosphatidylcholine-phosphatidylserine vesicles. Correlation by calorimetric and fusion measurements. Biochemistry 23, 3241-3247. doi: 10.1021/bi00309a019

Silvius, J. R., and Gagne, J. (1984b). Lipid phase behavior and calciuminduced fusion of phosphatidylethanolamine-phosphatidylserine vesicles. Calorimetric and fusion studies. Biochemistry 23, 3232-3240. doi: 10.1021/bi00 $309 \mathrm{a} 018$

Sohlenkamp, C., and Geiger, O. (2015). Bacterial membrane lipids: diversity in structures and pathways. FEMS Microbiol. Rev. 40, 133-159. doi: 10.1093/femsre/fuv008

Soumpasis, D. M. (1983). Theoretical analysis of fluorescence photobleaching recovery experiments. Biophys. J. 41, 95-97. doi: 10.1016/S0006-3495(83)84410-5

Sumitomo, K., and Oshima, A. (2017). Liquid-ordered/liquid-crystalline phase separation at a lipid bilayer suspended over microwells. Langmuir 33, 13277-13283. doi: 10.1021/acs.langmuir.7b02156

Tamm, L. K., and McConnell, H. M. (1985). Supported phospholipid bilayers. Biophys. J. 47, 105-113. doi: 10.1016/S0006-3495(85) 83882-0

Tero, R. (2012). Substrate effects on the formation process, structure and physicochemical properties of supported lipid bilayers. Materials 5, 2658-2680. doi: $10.3390 / \mathrm{ma} 5122658$

Tero, R., Fukumoto, K., Motegi, T., Yoshida, M., Niwano, M., and Hirano-Iwata, A. (2017). Formation of cell membrane component domains in artificial lipid bilayer. Sci. Rep. 7:17905. doi: 10.1038/s41598-017-18242-9

Tero, R., Ujihara, T., and Urisu, T. (2008). Lipid bilayer membrane with atomic step structure: supported bilayer on a step-and-terrace $\mathrm{TiO} 2(100)$ surface. Langmuir 24, 11567-11576. doi: 10.1021/la801080f

Unsay, J. D., Cosentino, K., Subburaj, Y., and García-Sáez, A. J. (2013). Cardiolipin effects on membrane structure and dynamics. Langmuir 29, 15878-15887. doi: $10.1021 / \mathrm{la} 402669 \mathrm{z}$

van Weerd, J., Karperien, M., and Jonkheijm, P. (2015). Supported lipid bilayers for the generation of dynamic cell-material interfaces. Adv. Healthc. Mater. 4, 2743-2779. doi: 10.1002/adhm.201500398

Zhong, J., and He, D. (2012). Recent progress in the application of atomic force microscopy for supported lipid bilayers. Chem. A Eur. J. 18, 4148-4155. doi: $10.1002 /$ chem.201102831

Conflict of Interest Statement: The authors declare that the research was conducted in the absence of any commercial or financial relationships that could be construed as a potential conflict of interest.

Copyright (c) 2018 Kakimoto and Tero. This is an open-access article distributed under the terms of the Creative Commons Attribution License (CC BY). The use, distribution or reproduction in other forums is permitted, provided the original author(s) and the copyright owner(s) are credited and that the original publication in this journal is cited, in accordance with accepted academic practice. No use, distribution or reproduction is permitted which does not comply with these terms. 